\title{
Epidural bolus injection with alkalinized lidocaine improves blockade of the first sacral segment - a brief report
}

\author{
[L'injection épidurale d'un bolus de lidocaïne alcalinisée améliore le blocage du \\ premier segment sacré - un résumé]
}

Masayuki Arakawa MD PhD, Yukio Aoyama MD PhD, Yoko Ohe MD PhD

Purpose: It has been reported that the addition of epinephrine and/or bicarbonate to local anesthetic enhances the depth of epidural blockade and that initial partial bolus injection results in greater caudal spread. We evaluated the anesthetic effects of lidocaine with epinephrine and/or bicarbonate injected into the epidural space by bolus or catheter injection.

Methods: Forty-four patients undergoing epidural anesthesia with $17 \mathrm{~mL}$ of $2 \%$ lidocaine containing 1:200,000 epinephrine at L4-5 or L5-SI were randomly divided into four groups. Lidocaine was administrated via epidural catheter [lidocaine catheter (LC) group] or Tuohy needle (lidocaine bolus group), lidocaine-bicarbonate was administrated via catheter (lidocaine-bicarbonate catheter group) or needle [lidocaine-bicarbonate bolus (LBB) group]. Pain threshold after repeated electrical stimulation was performed at L2 and SI regions. Motor blockade was evaluated using the Bromage scale. Sympathetic blockade was assessed with plethysmographic waveforms from the toe.

Results: The pain threshold of the SI dermatome in LBB group was significantly higher than in the lidocaine only groups, however, differences in the pain threshold at the L2 dermatome among the groups were insignificant. The onset of sensory blockade in the SI dermatome in the LBB group was significantly shorter than in the LC group. Significantly greater motor blockade was achieved in the lidocaine-bicarbonate groups than in the lidocaine-only groups. The amplitude of plethysmographic waveforms significantly increased within each group.

Conclusion: Epidural bolus injection of lidocaine-bicarbonate with epinephrine improves the pain threshold and speeds the onset of the blockade of the first sacral region.
Objectif : Il a été montré que l'addition d'épinéphrine et/ou de bicarbonate à l'anesthésique local améliore la profondeur du blocage épidural et que l'injection initiale d'un bolus partiel augmente l'étendue caudale de l'anesthésie. Nous avons évalué les effets anesthésiques de la lidocaïne, avec épinéphrine et/ou bicarbonate, injecté en bolus ou par cathéter dans l'espace épidural.

Méthode : Quarante-quatre patients devant subir une anesthésie épidurale, avec $17 \mathrm{~mL}$ de lidocaïne à $2 \%$ contenant de l'épinéphrine à I:200 000, au niveau de L4-5 ou L5-SI, ont été répartis au hasard en quatre groupes. La lidocaine a été donnée par cathéter épidural [groupe avec cathéter de lidocaïne (CL)] ou aiguille Tuohy (groupe avec bolus de lidocaïne). Le mélange lidocaïne-bicarbonate a été administré par cathéter (groupe avec cathéter de lidocaïne-bicarbonate) ou aiguille [groupe avec bolus de lidocaïne-bicarbonate (BLB)]. Le seuil de douleur a été établi à L2 et à SI par des stimulations électriques répétées. Le blocage moteur a été évalué à l'aide de l'échelle de Bromage, et le blocage sympathique grâce à la pléthysmographie de l'orteil.

Résultats : Chez les patients du groupe BLB, le seuil de douleur à SI $a$ été significativement plus élevé que chez les patients des groupes avec lidocaïne seule même si les différences de seuil de douleur intergroupes n'étaient pas significatives à $L 2$. Dans le groupe $B L B$, le délai d'installation du blocage à SI été significativement plus court que dans le groupe CL. Un blocage moteur sensiblement plus important a été réalisé avec le mélange lidocaïne-bicarbonate comparé à la lidocaïne seule. L'amplitude des ondes pléthysmographiques a augmenté de manière significative dans chaque groupe.

Conclusion : L'injection épidurale de bolus de lidocaïne-bicarbonate avec de l'épinéphrine élève le seuil de douleur et réduit le délai d'installation du blocage du premier segment sacré.

From the Second Department of Anesthesiology, Toho University School of Medicine, Tokyo, Japan. Address correspondence to: Dr. Masayuki Arakawa, Second Department of Anesthesiology, Toho University School of Medicine, 2-17-6 Ohashi, Meguro-ward, Tokyo 153-8515, Japan. Phone: +81-03-3468-1251; Fax: +81-03-3481-7336; E-mail: atruth@oha.toho-u.ac.jp Support was provided solely from institutional and/or department sources. Accepted for publication January 14, 2002.

Revision accepted March 18, 2002. 


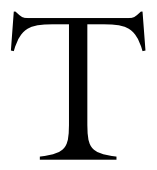

HE blockade of fifth lumbar and first sacral roots by epidural anesthesia often is delayed or incomplete. ${ }^{1}$ On the other hand, the addition of epinephrine and/or bicarbonate to local anesthetic enhances the depth of epidural blockade, ${ }^{2}$ reduces the onset time ${ }^{3,4}$ and the initial partial bolus injection of local anesthetic results in greater caudal spread. ${ }^{5}$

We compared the clinical efficacy (analgesia, motor block, and sympathetic block) of sodium bicarbonate and epinephrine added to lidocaine with that of epinephrine added to lidocaine (administered either by epidural bolus or catheter) in lumbar epidural anesthesia. Repeated electrical stimulation enables a quantification of analgesia, and the induction of temporal summation may render this test closer to clinical pain. ${ }^{2,6}$ Temporal summation occurs when the repetition of a peripheral stimulus causes increased and prolonged firing of dorsal horn neurons (central sensitization).

\section{Methods}

The sample size was determined based on estimations of the primary efficiency endpoint/pain threshold after repeated electrical stimulation. A difference of 30 $\mathrm{mA}$ in pain threshold was determined to be of clinical interest and the standard deviation has been reported to be $25 \mathrm{~mA} .{ }^{6}$ Eleven patients per group were considered necessary to achieve statistical significance $(\alpha=$ 0.05 and $l-B=0.8$ ).

After obtaining informed consent, 44 patients with ASA physical status I-II undergoing epidural anesthesia at L4-5 or L5-S1 were randomly divided into four groups according to the type of anesthetic solution and mode of administration. The epinephrine $(1: 200,000)$ was freshly added at the time of administration in all groups. The solutions were as follows: lidocaine $[20 \mathrm{~mL}$ of $2 \%$ xylocaine; (Astra Zeneca, Osaka, Japan) plus $2 \mathrm{~mL}$ of saline $0.9 \%$ ] and lidocaine-bicarbonate $(20 \mathrm{~mL}$ of $2 \%$ xylocaine plus $2 \mathrm{~mL}$ of sodium bicarbonate $8.4 \%$ added immediately before injection). Lidocaine was administrated via the epidural catheter; lidocaine catheter (LC) group or via the Tuohy needle; lidocaine bolus (LB) group. Lidocaine-bicarbonate was administrated via catheter; lidocaine-bicarbonate catheter (LBC) group or needle; lidocaine-bicarbonate bolus (LBB) group.

A pulse oximeter probe was applied to a big toe. Plethysmographic waveforms were recorded before and after epidural injection (Datex AS $/ 3^{\mathrm{TM}}$, Helsinki, Finland). The increment of pulse amplitude is an objective detector of early effects during epidural anesthesia. ${ }^{7}$ After $3 \mathrm{~mL}$ of $2 \%$ lidocaine were administrated as a test dose, $14 \mathrm{~mL}$ of the anesthetic solutions were injected through the catheter or the needle. The time at which the study drug injection ended was termed "time zero" for the purpose of subsequent patient assessment. The $\mathrm{pH}$ of lidocaine was determined by a $\mathrm{pH}$ meter (Shimadzu, Kyoto, Japan).

It has been reported that a train-of-five pulses at 2 $\mathrm{Hz}$ evoke temporal summation, ${ }^{6}$ as do two pulses at 0.5 $\mathrm{Hz}$ or three pulses at $1 \mathrm{~Hz} .{ }^{8}$ Based on these findings, it is possible to use a train-of-four pulses to assess pain threshold. In this study, we used four stimuli at $2 \mathrm{~Hz}$ delivered by the TOF GUARD ${ }^{\mathrm{TM}}$ (Biometer International, Odense, Denmark), designed originally to evaluate neuromuscular blockade. Bipolar surface $\mathrm{Ag}-\mathrm{AgCl}$ electrodes were placed at the SI dermatome (the lateral malleolus) as an index of caudal spread and L2 (the ventral femoral region) as an index of cephalad spread. A $200 \mu \mathrm{sec}$ square wave impulse was used as a single stimulus. To determine the threshold for temporal summation, the single stimulus was repeated four times at $2 \mathrm{~Hz}$, and current intensity was increased from $5 \mathrm{~mA}$ in steps of $1-5 \mathrm{~mA}$ until summation (perception of the last stimulus was perceived as painful) was observed, or a maximum current of $60 \mathrm{~mA}$ was reached. The test was repeated at the dermatomes L2 and $\mathrm{Sl}$ at zero, five, ten, 15 , and $20 \mathrm{~min}$.

The pinprick test was repeated at the dermatomes L2 and $\mathrm{Sl}$ at five, ten, 15, and $20 \mathrm{~min}$. The level of anesthesia was assessed at $20 \mathrm{~min}$ by loss of cold sensation. Both pinprick test and cold sensitivity were defined as abolished discrimination. Motor blockade was recorded with the Bromage scale $(0=$ full flexion of feet and knees, $\mathrm{l}=$ just able to move knees, $2=$ able to move feet only, and $3=$ unable to move feet or knees) at five, ten, 15 , and $20 \mathrm{~min}$. The onset of sensory blockade was defined as the time between "time zero" and the abolition of the pinprick response.

Differences among the groups were analyzed with one way analysis of variance (ANOVA) or KruskalWallis test as appropriate. The paired t test was used for differences of hemodynamic data and amplitude of plethysmographic waveforms within the groups. Pain threshold and amplitude of plethysmographic waveforms among the groups were compared by repeated measures of ANOVA. Bromage scale was compared by the Kruskal-Wallis test. Bonferroni adjustment was made for multiple comparisons. Analysis for the onset of sensory blockade was performed by survival analysis. The log rank test was used for comparisons among the groups. Results are expressed as means and SD were considered significant when $P<0.05$.

\section{Results}

Two patients were excluded from this study because the cephalad level of anesthesia attained only the L2 der- 
TABLE I Patient demographic data

\begin{tabular}{|c|c|c|c|c|}
\hline & $\begin{array}{l}\text { Lidocaine catheter } \\
\text { group }(n=10)\end{array}$ & $\begin{array}{l}\text { Lidocaine bolus } \\
\text { group }(n=10)\end{array}$ & $\begin{array}{l}\text { Lidocaine-bicarbonate } \\
\text { catheter group }(n=11)\end{array}$ & $\begin{array}{l}\text { Lidocaine-bicarbonate } \\
\text { bolus group }(n=11)\end{array}$ \\
\hline Height $(\mathrm{cm})$ & $160.6 \pm 7.5$ & $164.1 \pm 11.2$ & $160.6 \pm 7.7$ & $165.6 \pm 9.9$ \\
\hline Cephalad level & $\mathrm{T} 10(\mathrm{~T} 4-\mathrm{L} 3)$ & T8 (T3-L3) & $\mathrm{T} 10(\mathrm{~T} 5-\mathrm{Ll})$ & $\mathrm{T} 10(\mathrm{~T} 4-\mathrm{L} 3)$ \\
\hline Caudal level & $S 4(S 1-5)$ & $S 4(S 1-5)$ & S5 (S4-5) & S5 (S4-5) \\
\hline Weight (kg) & $56.9 \pm 11.1$ & $63.0 \pm 13.0$ & $59.2 \pm 12.6$ & $60.9 \pm 9.2$ \\
\hline Age $(\mathrm{yr})$ & $45.2 \pm 15.5$ & $44.7 \pm 12.1$ & $43.4 \pm 10.7$ & $43.6 \pm 17.4$ \\
\hline Gender (male/female) & $(5 / 5)$ & $(5 / 5)$ & $(3 / 8)$ & $(6 / 5)$ \\
\hline $\mathrm{pH}$ & $6.55 \pm 0.04$ & $6.54 \pm 0.05$ & $7.44 \pm 0.08^{* *}$ & $7.44 \pm 0.07 * *$ \\
\hline $\begin{array}{l}\text { Fluid administration \# } \\
\left(\mathrm{mL} \cdot \mathrm{kg}^{-1} \cdot \mathrm{hr}^{-1}\right)\end{array}$ & $9.5 \pm 4.5$ & $10.7 \pm 4.0$ & $8.8 \pm 4.8$ & $11.0 \pm 3.9$ \\
\hline \multicolumn{5}{|l|}{ Type of surgery } \\
\hline - General surgery & 1 & 1 & 5 & 4 \\
\hline - Gynecology & 3 & 5 & 4 & 5 \\
\hline - Orthopedics & 6 & 4 & 2 & 2 \\
\hline
\end{tabular}

Values are mean \pm SD. Cephalad and caudal level are median (range). \#Fluid administration volume was during the first hour after induction. ${ }^{*} P<0.01$ compared with lidocaine catheter group and lidocaine bolus group.

TABLE II Hemodynamic data and pulse amplitude multiples

\begin{tabular}{|c|c|c|c|}
\hline & & Before induction & $\begin{array}{l}20 \text { min after } \\
\text { epidural injection }\end{array}$ \\
\hline \multirow[t]{3}{*}{ Lidocaine catheter group } & $\mathrm{MAP}(\mathrm{mmHg})$ & $100.4 \pm 16.0$ & $85.7 \pm 14.2^{* *}$ \\
\hline & $\mathrm{HR}$ (beats. $\mathrm{min}^{-1}$ ) & $69.5 \pm 9.1$ & $77.7 \pm 11.6 \# \#$ \\
\hline & Pulse amplitude multiples & 1 & $4.1 \pm 3.9 \dagger$ \\
\hline \multirow[t]{3}{*}{ Lidocaine bolus group } & $\mathrm{MAP}(\mathrm{mmHg})$ & $95.7 \pm 18.4$ & $86.4 \pm 19.5^{*}$ \\
\hline & $\mathrm{HR}$ (beats. $\mathrm{min}^{-1}$ ) & $77.0 \pm 16.0$ & $89.7 \pm 20.6 \# \#$ \\
\hline & Pulse amplitude multiples & 1 & $2.7 \pm 1.7 \dagger$ \\
\hline Lidocaine-bicarbonate & $\mathrm{MAP}(\mathrm{mmHg})$ & $95.2 \pm 14.1$ & $79.8 \pm 9.4$ * \\
\hline \multirow[t]{2}{*}{ catheter group } & HR (beats. min $^{-1}$ ) & $67.1 \pm 11.9$ & $81.4 \pm 10.4 \# \#$ \\
\hline & Pulse amplitude multiples & 1 & $4.2 \pm 2.0 \dagger$ \\
\hline Lidocaine-bicarbonate & $\mathrm{MAP}(\mathrm{mmHg})$ & $90.8 \pm 13.3$ & $83.5 \pm 13.2^{*}$ \\
\hline \multirow[t]{2}{*}{ bolus group } & $\mathrm{HR}$ (beats. $\mathrm{min}^{-1}$ ) & $81.2 \pm 14.7$ & $92.2 \pm 17.4 \# \#$ \\
\hline & Pulse amplitude multiples & 1 & $3.7 \pm 2.8 \dagger$ \\
\hline
\end{tabular}

Values are mean $\pm \mathrm{SD} . \mathrm{MAP}=$ mean arterial pressure; $\mathrm{HR}=$ heart rate. ${ }^{*} P<0.05,{ }^{*} P<0.01$ and $\# \# P<0.01$ after 20 min compared with "before induction" in each group. $\dagger P<0.05$ after 20 min compared with "before induction" in each group.

matome. Demographic data and hemodynamic data were comparable among the groups (Tables I, II). The $\mathrm{pH}$ of lidocaine in the LBC and LBB groups was significantly higher than in the LC and LB groups (Table I). Mean arterial blood pressure decreased and heart rate increased within each group after $20 \mathrm{~min}$ (Table II). The pain threshold in the SI dermatome in the LBB group was significantly higher than in the LC and LB groups (Figure 1-B). Motor blockade assessed by the Bromage scale was significantly higher in the LBC and LBB groups than in the LC and LB groups (Figure 1-C).

The onset of sensory blockade in the $\mathrm{Sl}$ dermatome in the LBB group was significantly shorter than in the LC group (Figure 2-B). There were no differences in the amplitude of the plethysmographic waveforms between the groups, however they increased significantly within each group after five minutes (Table II).

\section{Discussion}

We have shown that epidural bolus injection of lidocaine with added bicarbonate and epinephrine increases the pain threshold and shortens the onset of blockade of the first sacral regions. The degree of motor blockade was enhanced by alkalinized lidocaine. When applied to a nerve membrane, a local anesthetic solution exists in two forms: as a nonionized free base and as a charged ionized cation. The change of $\mathrm{pH}$ increases the extraneural amount of nonionized lidocaine, the form that diffuses through the lipid phase of the neural membrane. An increase in the nonionized fraction of the local anesthetic (which 


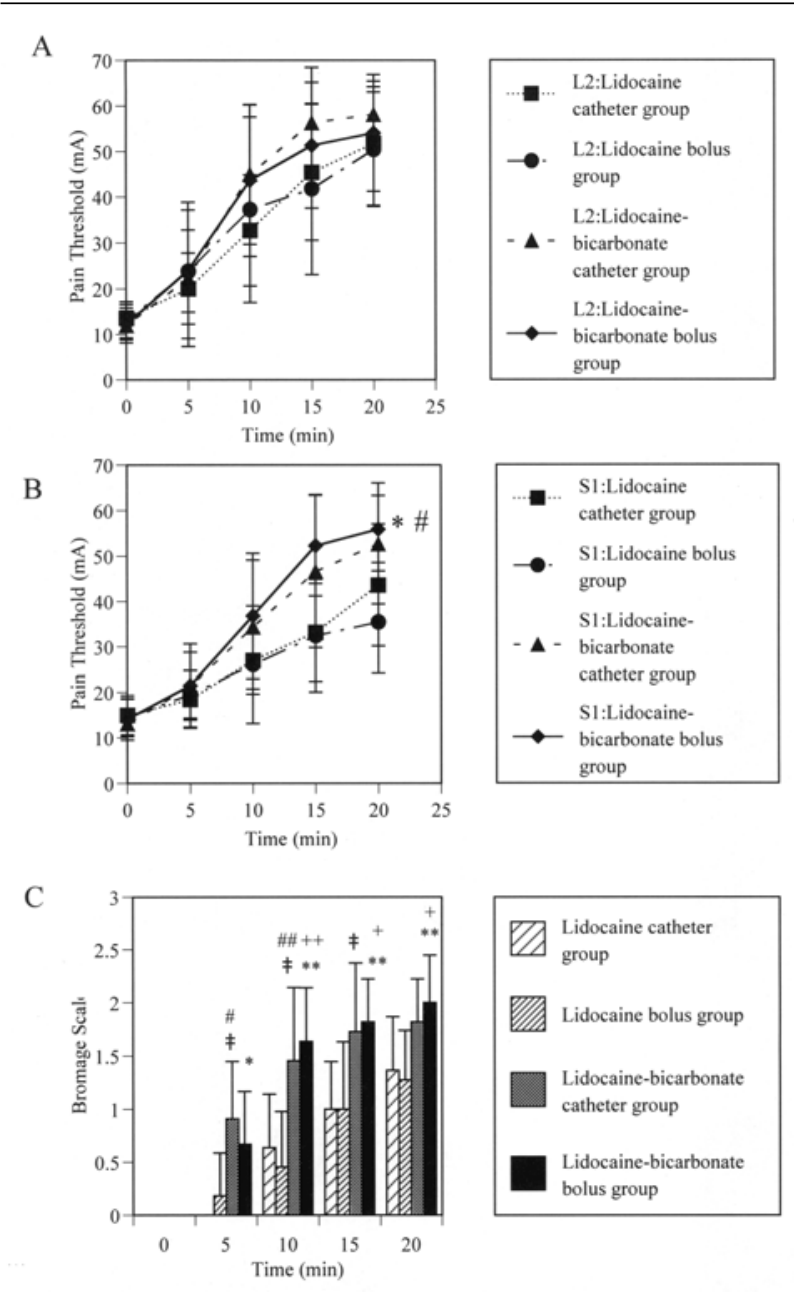

FIGURE 1 Changes in pain threshold (A, B). A: L2 dermatome. There were no significant differences among the groups. B: SI dermatome. ${ }^{*} P<0.05$ compared with the lidocaine catheter (LC) group. $\# P<0.05$ compared with the lidocaine bolus $(\mathrm{LB})$ group. Changes of the Bromage scale $(\mathrm{C})$. The score significantly increased after ten minutes compared with zero minutes within the lidocaine only groups $(P<0.05$; symbols not shown $)$, the score significantly increased after five minutes compared with zero minutes within the lidocaine-bicarbonate groups $(P<0.05$; symbols not shown). ${ }^{*} P<0.05,{ }^{*} P<0.01$ compared with LC group. $\ddagger P<0.01$ compared with LC group. $+P<0.05,++P<$ 0.01 compared with LB group. $\# P<0.05, \# \# P<0.01$ compared with LB group. Values are mean \pm SD.

is associated with an increase in $\mathrm{pH}$ ) results in improved nerve penetration and a more rapid onset of nerve blockade. ${ }^{9,10}$

Why bolus injection with alkalinized lidocaine was superior to the other three lidocaine administration techniques is not clear. Epidural catheter inserted $3 \mathrm{~cm}$ into the lumber spinal canal from a skin puncture most
A

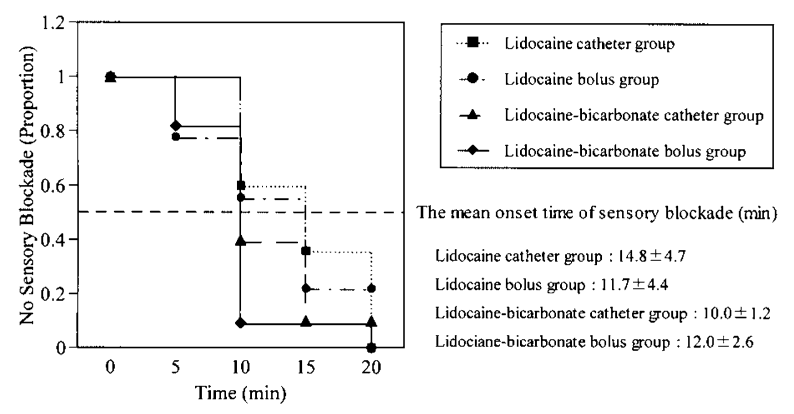

B

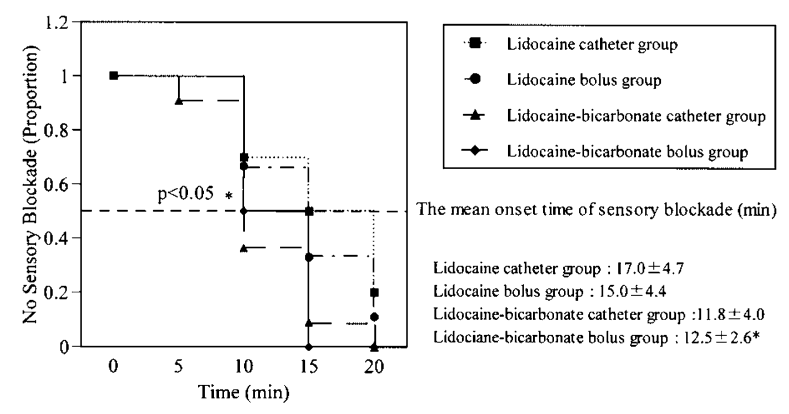

FIGURE 2 The onset of sensory blockade (survival analysis; Kaplan-Meier curves). A: L2 dermatome. There were no significant differences among the groups. B: SI dermatome. ${ }^{*} P<0.05 \mathrm{com}-$ pared with lidocaine catheter (LC) group. Values are mean \pm SD.

commonly travels to a site in the lateral epidural space by computed tomography. ${ }^{11}$ In case of epidural catheter insertion, there is a possibility that a variety of catheter tip locations could affect the quality of epidural blockade. If we accept the possibility that local anesthetics spread more cephalad than caudally after a bolus injection compared with injection via a catheter because the threshold in Sl dermatome was the lowest in the lidocaine bolus group, we suppose that bolus injection caused more local anesthetic to accumulate at L2 (cephalad) in the epidural space. More alkalinized local anesthetic diffused across the meninges and blocked SI nerve roots in a shorter time.

Temporal summation is not blocked by $0.5 \%$ bupivacaine epidural anesthesia, ${ }^{12}$ contrary to spinal anesthesia with plain bupivacaine $0.5 \%$ where the pain response to repeated stimulation disappeared at the sural nerve. ${ }^{13}$ Our results suggest that epidural anesthesia with alkalinized $2 \%$ lidocaine and epinephrine may inhibit temporal summation also. Protection of sensory neurons against central sensitization may offer 
relief from pain occurring after injury or surgery. ${ }^{14}$ Thus, our results suggest that alkalinization, by enhancing the quality of the block, may contribute to preemptive analgesia.

Bicarbonate was added to the lidocaine solution immediately prior to injection and precipitation was not a problem. However, precipitation has been reported ten minutes after the addition of $2 \mathrm{~mL}$ of sodium bicarbonate to $20 \mathrm{~mL}$ of lidocaine. ${ }^{15}$ The significance of this finding in the clinical context remains unclear but warrants further attention.

We conclude that bolus injection of lidocaine with added bicarbonate and 1: 200,000 epinephrine increases the pain threshold, improves analgesia and reduces the onset of blockade of the first sacral segment. Further studies on the most appropriate dose of bicarbonate will be necessary.

\section{Acknowledgement}

We gratefully acknowledge the helpful suggestions of Professor Lars Arendt-Nielsen, Center for SensoryMotor Interaction, Laboratory for Experimental Pain Research, Aalborg University, Aalborg East, Denmark.

\section{References}

1 Cousins MJ, Veering BT. Epidural neural blockade. In: Cousins MJ, Bridenbaugh PO, (Eds.). Neural Blockade in Clinical Anesthesia and Management of Pain, $3^{\text {rd }}$ ed. Philadelphia: JB Lippincott, 1998: 243-321.

2 Curatolo M, Petersen-Felix S, Arendt-Nielsen L, et al. Adding sodium bicarbonate to lidocaine enhances the depth of epidural blockade. Anesth Analg 1998; 86: 341-7.

3 DiFazio CA, Carron H, Grosslight KR, Moscicki JC, Bolding WR, Johns $\mathrm{RA}$. Comparison of $\mathrm{pH}$-adjusted lidocaine solutions for epidural anesthesia. Anesth Analg 1986; 65: 760-4.

4 Benzon HT, Toleikis JR, Dixit P, Goodman I, Hill JA. Onset, intensity of blockade and somatosensory evoked potential changes of the lumbosacral dermatomes after epidural anesthesia with alkalinized lidocaine. Anesth Analg 1993; 76: 328-32.

5 Asato F, Hirakawa N, Araki K, et al. A technique for obtaining successful sacral spread with continuous lumbar epidural anesthesia. Anesth Analg 1990; 70: 662-4.

6 Arendt-Nielsen L, Brennum J, Sindrup S, Bak P. Electrophysiological and psychophysical quantification of temporal summation in the human nociceptive system. Eur J Appl Physiol 1994; 68: 266-73.

7 Mineo $R$, Sharrock NE. Pulse oximeter waveforms from the finger and toe during lumbar epidural anesthesia. Reg Anesth 1993; 18: 106-9.
8 Arendt-Nielsen L, Sonnenborg FA, Andersen OK. Facilitation of the withdrawal reflex by repeated transcutaneous electrical stimulation: an experimental study on central integration in humans. Eur J Appl Physiol 2000; 81: 165-73.

9 Strobel GE, Bianchi CP. The effects of $\mathrm{pH}$ gradients on the action of procaine and lidocaine in intact and desheathed sciatic nerves. J Pharmacol Exp Ther 1970; 172: 1-17.

10 Strobel GE, Bianchi CP. The effects of $\mathrm{pH}$ gradients on the uptake and distribution of $\mathrm{Cl} 4$-procaine and lidocaine in intact and desheathed sciatic nerve trunks. J Pharmacol Exp Ther 1970; 172: 18-32.

11 Hogan Q. Epidural anatomy: new observations. Can J Anaesth 1998, 45: R40-4.

12 Curatolo M, Petersen-Felix S, Arendt-Nielsen L, Fischer $M$, Zbinden AM. Temporal summation during extradural anaesthesia. Br J Anaesth 1995; 75: 634-5.

13 Curatolo M, Petersen-Felix S, Arendt-Nielsen L, Zbinden $A M$. Spinal anaesthesia inhibits central temporal summation. Br J Anaesth 1997; 78: 88-9.

14 Wall PD. The prevention of postoperative pain. Pain 1988; 33: 289-90.

15 Koitabashi T, Sekiguchi H, Miyao H, Kawasaki J, Kawazoe T. Precipitation of $\mathrm{pH}$-adjusted local anesthetics with sodium bicarbonate (Japanese). Masui 1995; 44: 15-20. 